\title{
Prevalence and predictors of HIV-related stigma among institutional- and community-based caregivers of orphans and vulnerable children living in five less-wealthy countries
}

Lynne C Messer ${ }^{1 *}$, Brian W Pence ${ }^{2}$, Kathryn Whetten ${ }^{2}$, Rachel Whetten ${ }^{2}$, Nathan Thielman ${ }^{3}$, Karen O'Donnell ${ }^{3}$, Jan Ostermann ${ }^{2}$

\begin{abstract}
Background: In the face of the HIV/AIDS epidemic that has contributed to the dramatic increase in orphans and abandoned children (OAC) worldwide, caregiver attitudes about HIV, and HIV-related stigma, are two attributes that may affect caregiving. Little research has considered the relationship between caregiver attributes and caregiverreported HIV-related stigma. In light of the paucity of this literature, this paper will describe HIV-related stigma among caregivers of OAC in five less wealthy nations.
\end{abstract}

Methods: Baseline data were collected between May 2006 through February 2008. The sample included 1,480 community-based and 192 institution-based caregivers. Characteristics of the community-based and institutionbased caregivers are described using means and standard deviations for continuous variables or counts and percentages for categorical variables. We fit logistic regression models, both for the full sample and separately for community-based and institution-based caregivers, to explore predictors of acceptance of HIV.

Results: Approximately $80 \%$ of both community-based and institution-based caregivers were female; and $84 \%$ of institution-based caregivers, compared to $66 \%$ of community-based caregivers, said that they would be willing to care for a relative with HIV. Similar proportions were reported when caregivers were asked if they were willing to let their child play with an HIV-infected child. In a multivariable model predicting willingness to care for an HIVinfected relative, adjusted for site fixed effects, being an institution-based caregiver was associated with greater willingness (less stigma) than community-based caregivers. Decreased willingness was reported by older respondents, while willingness increased with greater formal education. In the adjusted models predicting willingness to allow one's child to play with an HIV-infected child, female gender and older age was associated with less willingness. However, willingness was positively associated with years of formal education.

Conclusions: The caregiver-child relationship is central to a child's development. OAC already face stigma as a result of their orphaned or abandoned status; the addition of HIV-related stigma represents a double burden for these children. Further research on the prevalence of HIV-related acceptance and stigma among caregivers and implications of such stigma for child development will be critical as the policy community responds to the global HIV/AIDS orphan crisis.

\footnotetext{
* Correspondence: lynne.messer@duke.edu

${ }^{1}$ Center for Health Policy and Inequalities Research; 2812 Erwin Rd, Suite 403;

Duke University Campus Box 90392; Durham NC 27705; USA

Full list of author information is available at the end of the article
} 


\section{Background}

The caregiver-child relationship has important longterm consequences for children's health and wellbeing. Attachment theorists consider children to have a need for a secure relationship with an adult caregiver for normal social and emotional development to occur $[1,2]$. Because orphans and abandoned children (OAC), defined as those who have had one or both parents die or were abandoned by both parents, lack one or more adult caregivers, their healthy development may be compromised.

Caregivers of OAC can contribute to their healthy development. While little research examining the characteristics of OAC caregivers exists, one study considered the reasons caregivers gave for fostering orphans. The authors found that the degree of relatedness toand financial capacity to care for- an orphan child among the most frequently cited reasons given for caregiving. However, child-level characteristics, like age and gender, were reportedly not considered in the decision to take on the care of an OAC [3]. Most caregivers were found to be female, older, poor, and living without a spouse.

In the face of the HIV/AIDS epidemic that has contributed to the dramatic increase in OAC worldwide [4,5], caregiver attitudes about HIV is one attribute that may affect the quality of OAC caregiving. Caregiver factors that have been previously associated with positive attitudes toward HIV/AIDS, orphans in general, and AIDS orphans in particular include middle age (35-44), polygamy, belief that there are increasing numbers of orphans in the community, having relatives or friends with HIV/AIDS and caregivers' knowledge regarding HIV/AIDS [6]. Concern about becoming infected with HIV/AIDS, however, also negatively affects willingness to serve as a caregiver to AIDS OAC [3].

When the caregiver or community's attitude toward HIV is negative, this attribute may manifest itself in HIV-related stigma. Stigma has been defined as an attribute that is significantly discrediting [7], which can have concrete material consequences. Research indicates stigma alters life chances, including income, employment, housing access, and health $[8,9]$. Experienced stigma can also result in adverse psychosocial consequences, including distress and depression [10-12]. HIVrelated stigma is prevalent. In a recent U.S. study with patients drawn from the HIV Cost and Services Utilization Study, all of the families interviewed recounted experiences with stigma, including $100 \%$ of mothers, $88 \%$ of fathers, $52 \%$ of children, $79 \%$ of adult children, and $60 \%$ of caregivers. About $97 \%$ of families described discrimination fears, $79 \%$ of families experienced actual discrimination, and $10 \%$ of uninfected family members experienced stigma from association with the parent with HIV [13]. Drivers of stigma include fear, availability and relevance of AIDS-related information, lack of social spaces to engage in dialogue about HIV/AIDS, perceived links between HIV/AIDS, sexual moralities and the control of women and young people, inadequate HIV/AIDS management services, and the ways in which poverty shapes people's reactions to HIV/AIDS [14]. Research suggests that stigma, and the resultant discrimination, can exacerbate the material and psychological problems children already face in the context of the HIV/AIDS pandemic [15-18]. Stigma can prevent proper access to education and care, both directly (through abuse, forced labor and inheritance loss) and indirectly (if children avoid potentially stigmatizing situations such as healthcare and educational interactions) [19]. When stigma is manifested in the OAC-caregiver relationship, through hostility, violence, or differential resource allocation, it can have severe negative impacts on children under care. While very little research has previously considered the extent of stigma expressed against children and youth infected with and affected by HIV/AIDS [20], one author reported significant associations between less expressed stigma behavior and higher knowledge of how to support HIV/AIDS infected persons [21].

In light of the dearth of literature considering caregiver attributes and HIV-related stigma, the goal of this paper is to describe HIV-related stigma among caregivers of $\mathrm{OAC}$ in five less wealthy nations.

\section{Methods}

\section{Study description}

The Positive Outcomes for Orphans (POFO) study is a longitudinal cross-cultural research study designed to identify characteristics of care associated with better child outcomes. For the purpose of this work, an orphan or abandoned child (OAC) is defined as a child living without one or more of his/her biological parent. The POFO study is following approximately 2,750 children who were between 6 to 12 years at study outset and their caregivers in 83 institutional care settings and 309 community clusters in six study sites across five less wealthy countries: Cambodia, India (two sites), Kenya, Tanzania, and Ethiopia. Additional study details are located elsewhere [22].

\section{Study sample}

Six geographically defined regions in five counties were chosen to represent cultural, historical, ethnic, religious, political, and geographic diversity. HIV prevalence differed across the countries as well. The 2007 estimated adult (15-49 years of age) HIV prevalence rate for each of the five study countries are as follows: Cambodia 
(0.8), India (0.3) with Nagaland estimated at more than twice that rate, Tanzania (6.2), Ethiopia (2.1) and Kenya (7.1-8.5) [23]. Two-stage random sampling survey methodology was used to identify a sample of institutionand community-living $\mathrm{OAC}$ ages 6 to 12 who were statistically representative of the population of institution- and community-living $\mathrm{OAC}$ in those regions.

\section{Institution Selection}

For each of the six study areas, comprehensive lists of all institutions were created. To ensure broad representation, institutions were defined as structures with at least five resident $\mathrm{OAC}$ from at least two different families not biologically related to the caregiver(s). The institutional sampling frame was generated through inquiries to local government officials, schools, and organizations working with orphans. Institutions specifically for street children, special needs children, and international adoption were excluded. In total, 83 institutions participated in the study with only three being located in a caregivers home and all having more than five OAC: nine in Battambang, Cambodia (one refused), 13 in Addis Ababa, Ethiopia (two refused), 13 in Kilimanjaro Region, Tanzania (one refused), 14 in Hyderabad, India (five refused), 15 in Dimapur and Kohima Districts of Nagaland, India (two refused), and 21 in Bungoma, Kenya (none refused). Reasons for refusal ranged from fear of psychological damage to the children to wanting monetary compensation for project participation.

\section{Selection of Institution-based Children}

Institutions provided a list of residential children aged 6 to 12 . Using a list of random numbers, up to 20 children per institution were randomly selected. When the target enrollment of 250 children could not be met at a particular site, for instance, in cases when there were not enough institutions from which only 20 children could be selected, then all children in the age range became eligible to participate. Of the 5,243 children cared for by the institutions, 2,396 were reported to be age-eligible, and 1,360 were selected for enrollment. The number of participating children per institution ranged from 1 to 51 .

\section{Community Sampling Area Selection}

The primary community sampling aim was to select an unbiased sample of community-based care settings. In each of the six study areas, 50 sampling areas ("clusters") were selected. Geographic or administrative boundaries were used to define sampling areas, therefore specific definitions varied across sites.

\section{Selection of Community-based Children}

A community-based OAC was an orphan or an abandoned child (living without either of his/her two parents) not living in an institution. In each sampling area up to five eligible children were selected, either randomly from available lists, or through a house-tohouse census conducted until five households with ageeligible children were identified. When the pre-identified sampling areas provided an insufficient number of community-based children, additional sampling areas were substituted; this occurred in 13 villages in Cambodia, 12 in Nagaland, and one in each of the remaining sites. In households with multiple age-eligible children, one child was selected as the child whose first name started with the earliest letter in the alphabet. In total, 1,463 community-based OAC were enrolled in the study.

\section{Caregiver Selection}

The children's (self-identified) primary caregivers were asked to respond to surveys about themselves and the children. In total, 193 institutional caregivers, ranging from 16 institutional caregivers in Nagaland to 52 in Cambodia, and 1,480 community-based caregivers participated in the assessments.

\section{Data collection protocol}

Baseline data collection was conducted between May 2006 and February 2008 among community-based and institution-based OAC and their caregivers. Four main baseline instruments collected information from: 1) children residing in communities who had a parent who had died or was missing; 2) children residing in institutions; 3 ) the children's primary caregivers; and 4) a person who could respond to administrative questions about the institution. Age inclusion criteria were based on survey instrument validity and pilot testing. Informed consent was obtained from each participating caregiver and from the heads of participating institutions. Assent was given by all participating children. Interviews were conducted with children and caregivers using their native language in the child's residence and children were interviewed. Ethical approval was provided by the Duke University Institutional Review Board (IRB) and by local and national IRBs in all participating countries.

\section{Study measures}

\section{HIV-related stigma and acceptance}

Caregivers were asked two questions: "If a relative of yours were sick with HIV, would you be willing to care for him or her"; and "Would you allow your child to play with an HIV-infected child". Caregivers could respond "yes," "no,", or "I don't know."

\section{Covariates}

Caregivers reported age, gender, marital status, and educational attainment, whether they earned any income (for institution-based caregivers: whether they earned any income outside the institution), and, for institution-based caregivers, the number of years they had been a caregiver. Caregivers also rated their own health on a five-point scale (very good, good, fair, poor, or very poor). 


\section{Analyses}

Characteristics of the community-based and institutionbased caregivers were described using means and standard deviations for continuous variables or counts and percentages for categorical variables. We fit logistic regression models, both for the full sample and separately for community-based and institution-based caregivers, to explore predictors of acceptance of HIV. The two stigma/acceptance variables were each coded so that the index category (coded as "1") corresponded to a response of "yes" (greater acceptance) while the reference category (coded as "0") corresponded to a response of either "no" or "I don't know." Thus an odds ratio greater than 1 in these models indicates a variable associated with greater acceptance. Logistic models included site fixed effects to account for the six recruitment sites. Analyses were conducted using Stata v.10.1.

\section{Results}

The sample included 1,480 community-based and 192 institution-based caregivers (Table 1). Approximately $80 \%$ of both community-based and institution-based caregivers were female, but institution-based caregivers tended to be older (mean age 42 vs. 35 years), more educated ( $88 \%$ with at least some secondary school education compared to $47 \%$ ), more likely to be never married ( $43 \%$ vs. $6 \%)$, more likely to report better health (75\% reporting good or very good health vs. $47 \%$ ) and less likely to be widowed (15\% vs. $61 \%)$. Eighty-four percent of institution-based caregivers compared to $66 \%$ of community-based caregivers said that they would be willing to care for a relative with HIV. A similar disparity was evident for the proportion of caregivers who said they would be willing to let their child play with an HIV-infected child ( $81 \%$ vs. 64\%). Only a small

Table 1 Caregiving-type-stratified characteristics of persons caring for orphans and abandoned children who comprise the POFO cohort

\begin{tabular}{|c|c|c|c|}
\hline \multirow[b]{2}{*}{ Characteristic } & \multicolumn{2}{|c|}{ Mean (SD) or $\mathrm{n}(\%)$} & \multirow[b]{2}{*}{ Missing } \\
\hline & Community caregivers & Institution caregivers & \\
\hline $\mathrm{N}$ & 1480 & 192 & \\
\hline Age, years (range: 11-89) & $41.7(13.5)$ & $35.3(11.1)$ & 246 \\
\hline Female gender & $1147(84.6 \%)$ & $146(77.3 \%)$ & 158 \\
\hline Years of education & & & 240 \\
\hline 0 & $323(24.8 \%)$ & $3(1.6 \%)$ & \\
\hline $1-6$ & $374(28.7 \%)$ & $20(10.8 \%)$ & \\
\hline $7-12$ & $552(42.4 \%)$ & $101(54.6 \%)$ & \\
\hline 13 or more & $53(4.1 \%)$ & $61(33.0 \%)$ & \\
\hline Marital status & & & 20 \\
\hline Never married & $85(5.8 \%)$ & $80(42.8 \%)$ & \\
\hline Currently married & $388(26.4 \%)$ & $63(33.7 \%)$ & \\
\hline Widowed & $898(61.1 \%)$ & $28(15.0 \%)$ & \\
\hline Other & $99(6.7 \%)$ & $16(8.6 \%)$ & \\
\hline Number of years as caregiver & N/A & $4.4(7.0)$ & 12 \\
\hline Any earned income* & $1039(71.0 \%)$ & $53(30.5 \%)$ & 40 \\
\hline Caregiver health status & & & 45 \\
\hline Very good & $126(8.7 \%)$ & $55(31.1 \%)$ & \\
\hline Good & $552(37.9 \%)$ & $77(43.5 \%)$ & \\
\hline Fair & $486(33.4 \%)$ & $38(21.5 \%)$ & \\
\hline Poor & $258(17.7 \%)$ & $7(4.0 \%)$ & \\
\hline Very poor & $35(2.4 \%)$ & $0(0.0 \%)$ & \\
\hline Would care for relative with HIV & & & 80 \\
\hline Yes & $934(65.5 \%)$ & $142(83.5 \%)$ & \\
\hline No & $369(25.9 \%)$ & $21(12.4 \%)$ & \\
\hline Don't know & $123(8.6 \%)$ & $7(4.1 \%)$ & \\
\hline Would allow child to play with HIV+ child & & & 76 \\
\hline Yes & $921(64.4 \%)$ & $137(81.1 \%)$ & \\
\hline No & $408(25.5 \%)$ & $26(15.4 \%)$ & \\
\hline Don't know & $101(7.1 \%)$ & $6(3.6)$ & \\
\hline
\end{tabular}

* For institutional caregivers: Any earned income outside institution 
proportion of caregivers responded "I don't know" to either question.

In a multivariable model predicting willingness to care for an HIV-infected relative, adjusted for site fixed effects (Table 2), being an institution-based caregiver appeared associated with greater willingness than community-based caregivers. Decreased willingness was reported by older respondents (adjusted odds ratio $(\mathrm{AOR})$ and $95 \%$ Confidence Interval $(95 \% \mathrm{CI})=0.9[0.8$, 1.0] for each 10-year age increment) and those reporting no education (AOR $=0.4 ; 95 \% \mathrm{CI}: 0.2,0.6$ ) while willingness increased with high levels of formal education (13 plus years). There was some suggestion that willingness increased with better health (AOR $=1.2 ; 95 \% \mathrm{CI}$ : $1.0,1.4)$ and varied by marital status, with currently married respondents being the most willing to care for an HIV-infected relative. In models stratified by caregiver setting (institution vs. community-based), older age was predictive of decreased willingness among community-based but not among institution-based caregivers. Low education (none) was associated with reduced willingness among both community- and institution-based caregivers, while better health was associated with greater acceptance among institution-based caregivers only. In most models currently married caregivers reported greater willingness than others, although the precision of these estimates was reduced in the stratified-model setting.

In the multivariable, site-fixed-effects models predicting willingness to allow one's child to play with an HIVinfected child (Table 3), female gender and older age was associated with less willingness $(\mathrm{AOR}=0.8$; 95\% CI:
0.7, 0.9 and AOR $=0.6$; 95\% CI: 0.4, 1.0, respectively). Willingness was also positively associated with years of formal education, with high education (13 plus years) being associated with increased odds of willingness. In the models stratified by caregiving location, young age and six or fewer years of education was associated with decreased willingness among community-based, but not among institution-based caregivers. Thirteen or more years of education was associated with increased willingness in both community-based and institution-based settings $(\mathrm{AOR}=3.4 ; 95 \% \mathrm{CI}: 1.5,7.6$ and 3.4; 95\% CI: 1.1 , 11.0 , respectively).

\section{Discussion}

In this paper, we considered two indicators of HIVrelated stigma in a sample of nearly 2,000 caregivers of orphans and abandoned children (OAC) in five less wealthy nations: willingness to care for a relative with HIV/AIDS in one's home and willingness to let one's child play with a child who is HIV-infected. Overall, relatively small proportions of caregivers reported HIVrelated stigma, with less stigma reported by institutionbased caregivers compared to community-based caregivers. More years of formal education was associated with greater caregiver acceptance (less stigma) among all caregivers. Older age and female gender were associated with decreased acceptance among communitybased but not institution-based caregivers.

The dramatic increase in the number of OAC worldwide, particularly as a result of the AIDS epidemic, has focused attention on the importance of the caregiving setting and the caregiver-OAC relationship in

Table 2 Combined and caregiving-type-stratified multivariable predictors of stigma among POFO caregivers: willingness to care for an HIV-infected relative

\begin{tabular}{|c|c|c|c|}
\hline & \multicolumn{3}{|c|}{ Would care for relative with HIV } \\
\hline & All caregivers & Community-based & Institution-based \\
\hline Institution-based caregiver & $1.74(0.94,3.20)$ & $\mathrm{N} / \mathrm{A}$ & N/A \\
\hline Age, per 10 years & $0.87(0.76,1.00)$ & $0.82(0.71,0.95)$ & $1.23(0.81,1.87)$ \\
\hline Female gender & $0.77(0.51,1.18)$ & $0.75(0.48,1.18)$ & $1.08(0.29,3.97)$ \\
\hline \multicolumn{4}{|l|}{ Years of education } \\
\hline None & $0.37(0.24,0.56)$ & $0.41(0.26,0.63)$ & $0.05(0.00,0.99)$ \\
\hline $1-6$ & $0.81(0.54,1.21)$ & $0.85(0.56,1.30)$ & $1.10(0.15,8.24)$ \\
\hline $7-12$ & 1.00 (ref) & 1.00 (ref) & 1.00 (ref) \\
\hline 13 or more & $2.02(1.08,3.78)$ & $2.41(1.08,5.38)$ & $2.33(0.68,7.93)$ \\
\hline \multicolumn{4}{|l|}{ Marital status } \\
\hline Currently married (ref) & 1.00 (ref) & 1.00 (ref) & 1.00 (ref) \\
\hline Never married & $0.63(0.34,1.14)$ & $0.45(0.22,0.93)$ & $1.42(0.41,4.87)$ \\
\hline Widowed & $0.64(0.44,0.92)$ & $0.58(0.39,0.86)$ & $0.58(0.12,2.85)$ \\
\hline Other & $0.42(0.22,0.81)$ & $0.39(0.19,0.80)$ & $0.69(0.11,4.35)$ \\
\hline Health (on 5-point scale) & $1.21(1.01,1.44)$ & $1.14(0.94,1.37)$ & $2.55(1.20,5.43)$ \\
\hline Any earned income & $0.83(0.57,1.21)$ & $0.74(0.50,1.11)$ & $2.26(0.46,11.17)$ \\
\hline Years as caregiver (\#) & $\mathrm{N} / \mathrm{A}$ & N/A & $0.29(0.03,2.73)$ \\
\hline
\end{tabular}


Table 3 Combined and caregiving-type-stratified multivariable predictors of stigma among POFO caregivers: willingness to let child play with an HIV-infected child

\begin{tabular}{|c|c|c|c|}
\hline & \multicolumn{3}{|c|}{ Would allow child to play with HIV+ child } \\
\hline & All caregivers & Community-based & Institution-based \\
\hline Institution-based caregiver & $0.77(0.42,1.40)$ & N/A & N/A \\
\hline Age, per 10 years & $0.82(0.71,0.93)$ & $0.78(0.68,0.90)$ & $0.95(0.64,1.41)$ \\
\hline Female gender & $0.63(0.41,0.97)$ & $0.63(0.40,1.01)$ & $0.71(0.20,2.52)$ \\
\hline \multicolumn{4}{|l|}{ Years of education } \\
\hline None & $0.26(0.17,0.39)$ & $0.27(0.18,0.42)$ & $0.37(0.02,6.00)$ \\
\hline $1-6$ & $0.53(0.35,0.80)$ & $0.51(0.33,0.79)$ & $1.13(0.21,6.17)$ \\
\hline $7-12$ & 1.00 (ref) & 1.00 (ref) & 1.00 (ref) \\
\hline 13 or more & $3.70(1.95,7.03)$ & $3.40(1.52,7.59)$ & $3.43(1.06,11.02)$ \\
\hline \multicolumn{4}{|l|}{ Marital status } \\
\hline Currently married (ref) & 1.00 (ref) & 1.00 (ref) & 1.00 (ref) \\
\hline Never married & $0.56(0.31,1.02)$ & $0.51(0.24,1.09)$ & $0.66(0.21,2.05)$ \\
\hline Widowed & $0.84(0.58,1.20)$ & $0.79(0.54,1.16)$ & $0.60(0.14,2.68)$ \\
\hline Other & $0.62(0.32,1.20)$ & $0.62(0.29,1.29)$ & $0.45(0.09,2.33)$ \\
\hline Health (on 5-point scale) & $1.05(0.88,1.26)$ & $1.03(0.85,1.24)$ & $1.41(0.78,2.58)$ \\
\hline Any earned income & $1.21(0.82,1.79)$ & $1.02(0.67,1.55)$ & $4.51(0.96,21.18)$ \\
\hline Years as caregiver (\#) & N/A & N/A & $0.39(0.07,2.27)$ \\
\hline
\end{tabular}

influencing child outcomes. HIV-related stigma is widespread and could plausibly affect the caregiver-OAC relationship for children infected with or orphaned by HIV. Yet no other literature exploring attributes of OAC caregivers and the relation of those attributes to HIV-related stigma was identified. Recent reviews by UNICEF, Save the Children (UK) and other agencies have underscored this critical gap in the literature. "In spite of ample anecdotal and descriptive evidence that HIV/AIDS-related stigma and discrimination are affecting children, not enough systematic research has been done to illustrate the nature and extent of the problem, and how it relates to other key sources of disadvantage for children in poor, high-prevalence areas" [24]. Recent policy statements have recommended de-emphasizing institution-based care in favor of community-based care settings on the basis that better child care will result $[25,26]$; in the present study, however, we found greater acceptance and less reported stigma among institutionbased compared to community-based caregivers. If HIVrelated stigma affects $\mathrm{OAC}$ caregiving, this finding may be important to the ongoing policy discussion.

Reducing stigma and quality HIV care are related. Preliminary data from research in rural Haiti suggest that the introduction of quality HIV care can lead to a rapid reduction in stigma, with resulting increased uptake of testing [27]. Other research suggests that people who live in a context where they see people with HIV/AIDS being treated with kindness and care are far more likely to acknowledge their vulnerability, to seek out information about how to protect themselves or go for voluntary counseling and testing, and to take precautions in their sexual relationships [14]. Therefore, it appears that stigma reduction and HIV care work synergistically to improve prevention and reduce risk.

Our ability to describe the prevalence and predictors of two markers of HIV stigma in a large sample of OAC caregivers from five less wealthy nations is a strength of this study. However, this work is also not without limitations. While caregivers were asked about HIV-related stigma, it is not clear if the OAC they were caring for were HIV-infected or if their parents had died from AIDS or AIDS-related complications. Prior qualitative work has indicated that in many parts of the world, AIDS-related deaths are often not reported as such by family members or friends, who instead may cite other causes of death, such as malaria or diarrhea [14]. We also were not able to examine whether caregivers' reports of HIV-related stigma was associated with differential child outcomes over time. Longitudinal data would shed important light on this question.

\section{Conclusion}

The caregiver-child relationship is central to a child's development. OAC already face stigma as a result of their orphaned or abandoned status; OAC affected by HIV, either by virtue of being infected themselves or because they were orphaned due to HIV, face a potential double burden of stigmatization. And many, if not most OAC, are not even aware of their HIV status or the status of their parents. Therefore, caring for OAC often carries with it the uncertainty of the child's status.

Stigma and stigmatization have been linked to reinforcement of social inequalities of class, race, gender, and 
sexuality [28]. While most caregivers reported willingness, or the absence of stigma, over $25 \%$ of caregivers willingly reported on their HIV-related stigma. Further research on the prevalence of HIV-related acceptance and stigma among caregivers, and the implications of such stigma for healthy child development, will be critical as the policy community develops appropriate responses to the global AIDS orphan crisis.

\section{List of abbreviations}

HIV: human immunodeficiency virus; AIDS: acquired immunodeficiency syndrome; OAC: orphaned and abandoned child/children; AOR: adjusted odds ratio; 95\% Cl: 95 percent confidence interval; UNICEF: United Nations Children's Fund; UK: United Kingdom.

\section{Acknowledgements}

The authors would like to acknowledge the members of the POFO Research Team: Chris Bernard Agala, Frehiwot Alebachew, Sisay W. Ameya, Robin Briggs, Sopheak Chan, Haimanot Diro, Belaynesh Engadawork, Dafrosa Itemba, Venkata Gopala Krishna Kaza, Rajeswara Rao Konjarla, Mao Lang, Dean Lewis, Ira Madan, Cyrilla Manya, Restituta Mrema, Kate Murphy-McMillian, Agnes Ngowi, Imliyanger Pongen, Pelevinuo Rai, John Shao, Neville Selhore, Amani Sizya Vanroth Vann, Augustine Wasonga. We also would like to acknowledge Anne Fletcher and Seema Parkash for their valuable and supportive assistance with this manuscript. Funding: This work was supported by the National Institute of Child Health and Development (NICHD), grant No. 5R01HD046345-04. The funders had no role in study design, data collection and analysis, decision to publish, or preparation of the manuscript.

\section{Author details}

'Center for Health Policy and Inequalities Research; 2812 Erwin Rd, Suite 403; Duke University Campus Box 90392; Durham NC 27705; USA. ${ }^{2}$ Center for Health Policy and Inequalities Research; Duke University; Durham NC USA. ${ }^{3}$ Duke University; Durham NC USA.

\section{Authors' contributions}

LCM: conceived of the analysis and wrote the manuscript. BWP: Coconceived of the analysis, conducted the statistical analysis and helped write the manuscript. KW: conceived of the study and helped to draft the manuscript. RW: conceived of the study, participated in the study design and coordination. NT: participated in the study design and coordination and helped to draft the manuscript. KOD: participated in the study design and coordination and helped to draft the manuscript. JO: participated in the study design and coordination and prepared data for analysis. All authors read and approved the final manuscript

\section{Competing interests}

The authors declare that they have no competing interests.

Received: 2 February 2010 Accepted: 19 August 2010

Published: 19 August 2010

\section{References}

1. Bowlby J: Attachment and Loss New York: Basic Books 1980, 3.

2. Bowlby J: Attachment and Loss New York: Basic Books, 2 1982, 2.

3. Howard B, Phillips C, Matinhure N, Goodman K, McCurdy S, Johnson C: Barriers and incentives to orphan care in a time of AIDS and economic crisis: a cross-sectional survey of caregivers in rural Zimbabwe. BMC Public Health 2006, 9(6).

4. UNICEF U, USAID: Children on the Brink: a joint report of new orphan estimates and a framework for action. 2004.

5. UNICEF: Child protection: child protection from violence, exploitation and abuse. Facts on Children UNICEF, May 20092009.

6. Ohnishi M, Nakamura K, Kizuki M, Seino K, Inose T, Takano T: Caregivers' and non-caregivers' knowledge regarding HIV/AIDS and attitude towards HIV/AIDS and orphans in Nigeria. Health and Social Care in the Community 2008, 16(5):483-492.
7. Goffman E: Stigma and Social Identity Englewood Cliffs, NJ: Prentice-Hall 1964.

8. Link B, Phelan J: Conceptualizing stigma. Annual Review of Sociology 2001, 27:363-385.

9. Madru N: Stigma and HIV: Does the social response affect the natural course of the epidemic? Journal of the Association of Nurses in AIDS Care 2003, 14(5):39-48.

10. Aggleton P: Barcelona 2002: law, ethics and human rights. HIV/AIDSrelated stigma and discrimination: a conceptual framework. Canadian HIV/AIDS Policy Law Review 2002, 7(2-3):115-116.

11. Crocker J, Major B, Steele C: Social Stigma. In The Handbook of Social Psychology. Edited by: Gilbert D, Fiske S, Lindzey G. Boston, MA: McGraw Hill; , 4 1998:2:504-553.

12. Fife $B$, Wright $E$ : The dimensionality of stigma: a comparison of its impact on the self of persons with HIV/AIDS and cancer. Journal of Health and Social Behavior 2000, 41(1):50-67.

13. Bogart L, Cowgill B, Kennedy D, Ryan G, Murphy D, Elijah J, Shchuster M: HIV-related stigma among people with HIV and their families: a qualitative analysis. AIDS and Behavior 2008, 12:244-254.

14. Campbell C, Nair Y, Maimane S, Nicholson J: 'Dying twice': a multilevel model of the roots of AIDS stigma in two South African communities. Journal of Health Psychology 2007, 12(3):403-417.

15. Gernholtz L, Richter M: Access of abandoned children and orphans with HIV/AIDS to antiretroviral therapy - a legal impasse. South African Medical Journal 2004, 94(11):910-912.

16. Geballe S, Gruendel J, Andiman W: Forgotten children of the AIDS epidemic New Haven, CT: Yale University Press 1995.

17. Clay S, Bond V, Nyblade L: We can tell them AIDS deosn't come through being together. Children's experiences of HIV and AIDS-related stigma in Zambia 2002-2003. Lusaka: Zambart Project and Kara Counseling and Training Trust 2003.

18. Chase E, Aggelton P: Stigma, HIV/AIDS and prevention of mother-to-child transmission: a pilot study in Zambia, INdia, Ukraine and Burkina Faso. UK: United Nations Children's Fund/Panos Institute 2001.

19. Strode A, Barrett-Grant K: The role of stigma and discrimination in increasing vulnerability of children and youth infected with and affected with HIV/AIDS. UK: Save the Children 2001.

20. Strode A, Grant $K$ : The role of stigma and discrimination in increasing the vulnerability of children and youth infected with and affected by HIV/ AIDS. Arcadia, South Africa: Save the Children (U.K.) 2001.

21. Hamra M, Ross M, Karuri K, Orrs M, D'Agostino A: The relationship between expressed HIV/AIDS-related stigma and beliefs and knowledge about care and support of people living with AIDS in families caring for HIV-infected children in Kenya. AIDS Care 2005, 17(7):911-922.

22. Center for Health Policy Homepage. Research and Grants, POFO.

23. UNAIDS, WHO, UNICEF: Epidemiological Fact Sheet on HIV and AIDS: Core data on epidmiology and response. Geneva, Switzerland 2009.

24. Deacon H, Stephney I: HIV/AIDS, stigma and children: a literature review. Cape Town, SA: Human Sciences Research Council 2007.

25. Richter L, Foster G, Sherr L: Where the heart is: meeting the psychosocial needs of young children in the context of HIV/AIDS. The Hague, The Netherlands: Bernard van Leer Foundation 2006.

26. UNICEF, UNAIDS, AID I: Communique. 2008, Paper presented at the Fourth Global Partners Forum.

27. Castro A, Farmer P: Understanding and addressing AIDS-related stigma: from anthropological theory to clinical practice in Haiti. American Journal of Public Health 2005, 95(1):53-59.

28. Parker R, Aggleton P: HIV and AIDS-related stigma and discrimination: a conceptual framework and implications for action. Social Science and Medicine 2003, 57:13-24.

\section{Pre-publication history}

The pre-publication history for this paper can be accessed here: http://www.biomedcentral.com/1471-2458/10/504/prepub

doi:10.1186/1471-2458-10-504

Cite this article as: Messer et al:: Prevalence and predictors of HIVrelated stigma among institutional- and community-based caregivers of orphans and vulnerable children living in five less-wealthy countries. BMC Public Health 2010 10:504. 